\title{
Frameworks to Set Priorities for Treatments Based on Cost-Effectiveness and Equity
}

\author{
Pedro Plans-Rubió*
}

\author{
Public Health Agency of Catalonia, Health Departament, Barcelona, Spain
}

\begin{abstract}
Two priority-setting frameworks to decide how to allocate limited resources among available treatments were developed, the first one based on cost-effectiveness and the second one based on cost-effectiveness and a social welfare function (SWF). The framework based on cost effectiveness gives a higher priority to therapies with lower average or incremental cost-effectiveness ratios. The framework based on cost effectiveness and a SWF takes into account social aversion to inequality in the distribution of health-related gains, and gives a higher priority to independent therapies associated with values of $\varepsilon$ consistent with the social welfare function. The framework to set priorities based on cost effectiveness maximizes effectiveness from available resources, but in non-utilitarian societies, it could not maximize health-related social welfare. The framework based on cost-effectiveness and a SWF maximizes health-related social welfare in non-utilitarian societies when several independent and mutually exclusive therapies are available. This framework can reduce health inequalities among different groups of patients, since it reduces the cost of treating all groups of patients with at least one therapy. In conclusion, the framework based on cost effectiveness could be used to decide priorities in utilitarian societies, and the framework based on cost effectiveness and a SWF could be used in non-utilitarian societies.
\end{abstract}

Keywords: Cost-effectiveness, efficiency, equity, priority setting, social welfare function.

\section{INTRODUCTION}

Decisions concerning the allocation of scarce health care resources require managers and doctors to choose between competing claims on health care services budgets. The development of frameworks to inform priority settingchoices between alternative amounts and types of health care-is one of the most important challenges facing both economists and health sector decision-makers.

Economic approaches to priority setting are based on the premise that it is possible to design a rational priority-setting system that will produce legitimate changes in resource allocation using the principles of opportunity cost and marginal analysis. So-called "orthodox" economic approaches suggest that priority setting is a relatively straightforward optimization problem: decision makers should seek to maximize health-related utility for their population subject to a resource scarcity constraint. That is, they adopt a utilitarian approach, for example, by seeking to maximize quality-adjusted life year (QALY) gains [1]. Resource allocation decisions are informed by incremental analysis of the cost per unit of health-related utility (e.g. cost per QALY) associated with alternative drug therapies within predefined budgets. The utilitarian approach is based on the following premises: 1) one unit of health-related gain (effectiveness) has the same value irrespective of who gains it; 2) more cost-effective drug therapies (low cost per unit of outcome) must have a higher priority than less cost-effective

*Address correspondence to this author at the Public Health Agency of Catalonia, Health Departament, Barcelona, Spain; Tel: 93551 36 82;

E-mail: pedro.plans@gencat.cat therapies; and 2) population health-related gains must be maximized from available resources.

The purpose of cost-effectiveness analysis is to help decision makers determine how to allocate resources across a number of competing drug therapies to maximize health outcomes from a given budget. Torrance [2] and Maynard [3] published examples of cost-effectiveness league tables, where therapies are ordered by their cost-effectiveness ratios. These tables can be used to set priorities for allocating resources, giving a higher priority to more cost-effective drug therapies $[4,5]$.

Nevertheless, cost-effectiveness league tables have been questioned because they do not account for distributional issues that are known to be important in the allocation of health care resources [6-26]. More specifically, the costeffectiveness approach does not account for the distribution of available resources and health-related gains among patients, or for the possibility of one group of patients not receiving any treatment at all.

A priority-setting approach based on efficiency and equity considerations would set priorities according to the perceived importance of expected health outcomes from available treatments [14]. Some authors have suggested using a strategy in which both the cost-effectiveness and the aversion to inequality in the distribution of health-related gains between groups of patients is taken into account [7, 15]. In this approach, priorities should be decided by taking into account criteria not included in the cost-effectiveness model. To date, however, consistent frameworks to set priorities for multiple drug therapies based on cost effectiveness and on both cost effectiveness and equity have not been developed. 
The objective of this study is to develop a priority-setting framework to decide allocation of scarce resources for a number of competing drug therapies based on cost effectiveness and a framework based on cost effectiveness and a social welfare function. These two frameworks are compared by applying them to a concrete resource allocation problem.

\section{METHODS}

\section{Ranking of Priorities Based on Cost-Effectiveness}

Prioritization based on cost-effectiveness has the objective of maximizing health-related gains from available resources. This objective is achieved by dividing competing pharmaceutical therapies into independent and mutually exclusive ones and giving higher priority to therapies with greater cost effectiveness (lower cost-effectiveness ratios) than to those with lower cost-effectiveness [4]. Independent drug therapies are defined as those that are available for different health problems or groups of patients, and mutually exclusive drug therapies are defined as those that are available for the same health problem or group of patients. The ranking of priorities for available therapies is decided based on the average cost-effectiveness ratios for independent pharmaceutical therapies and the incremental costeffectiveness ratios for mutually exclusive ones [4]. The average cost-effectiveness ratio is obtained by dividing the total cost by the total effectiveness, and the incremental costeffectiveness ratio is obtained by dividing the incremental cost by the incremental effectiveness of compared therapies: $\operatorname{cost}_{\mathrm{A}^{-}}$ $\operatorname{cost}_{\mathrm{B}} /$ effectiveness $\mathrm{A}_{\mathrm{A}}$-effectiveness ${ }_{\mathrm{B}}$.

For independent pharmaceutical therapies, the ranking of priorities is decided by giving a higher priority to therapies with lower average cost-effectiveness ratios, as they provide effectiveness units at a lower cost than do interventions with higher ratios. The cost-effectiveness ratio must be, on the other hand, lower than the critical cost-effectiveness threshold representing the highest price per effectiveness unit that society is willing to pay $[5,27]$. The critical costeffectiveness ratio ranges from $€ 20,000-50,000 / \mathrm{Q} A L Y$ or LYG, with a value of $20,000-30,000$ per QALY in the United Kingdom [28], \$50,000 per QALY in the United States of America [29], and Ca\$30,000-100,000 per QALY in Canada [30].

For mutually exclusive pharmaceutical therapies, the ranking of priorities is determined by means of the following steps: 1) Mutually exclusive therapies with a lower effectiveness and a higher or equal cost than other available therapies are eliminated from the ranking of priorities due to complete dominance. If therapy $\mathrm{A}$ has a higher effectiveness and lower cost than therapy $\mathrm{B}$, then therapy $\mathrm{A}$ has a complete dominance over B because it provides health-related gains at a lower cost than therapy B. 2) Mutually exclusive drug therapies without a complete dominance are ranked according to healthrelated gains and the incremental cost-effectiveness ratio for each subsequent more effective therapy is calculated. 3) When one incremental cost-effectiveness ratio is lower than the previous one in the sequence of increasingly effective mutually exclusive therapies, then the less effective therapy is eliminated from the ranking of priorities due to extended dominance, and the incremental cost-effectiveness ratio is recalculated. If therapy A has a higher effectiveness and higher cost than therapy $\mathrm{B}$ and the incremental cost-effectiveness ratio of $\mathrm{A}$ is lower than the cost-effectiveness ratio of B, then therapy A has an extended dominance over $\mathrm{B}$ because it provides additional effectiveness units at a lower cost than B. 4) The final ranking of mutually exclusive therapies must include only a sequence of therapies with increasingly incremental cost-effectiveness ratios. A higher priority is then given to mutually exclusive therapies with lower incremental cost-effectiveness ratios.

The ranking of priorities among independent and mutually exclusive pharmaceutical therapies is determined by giving a higher priority to pharmaceutical therapies with lower incremental or average cost-effectiveness ratios than to those with higher ratios. Based on the decision making rules for cost-effectiveness analysis, the optimal strategy is to allocate resources to pharmaceutical therapies following the ranking list until they are exhausted, selecting only one mutually exclusive intervention for each group of mutually exclusive therapies. This strategy maximizes health-related gains from available resources. If a fixed budget must be allocated among several independent $(i=1, \ldots n)$ and mutually exclusive $(\mathrm{j}=1, \ldots \mathrm{m})$ pharmaceutical therapies, the health maximization objective is achieved using the framework proposed since it may solve the following equations:

$$
\begin{aligned}
& \text { Max.Effectiveness }=\sum_{i=1}^{n} \frac{\text { Costs (i) }}{\text { Cost effectiveness (i) }}+ \\
& \qquad \sum_{\mathrm{j}=1}^{m} \frac{\text { Costs (j) }}{\text { Incremental cost effectiveness (j) }} \\
& \text { Budget } \geq \sum_{\mathrm{i}=1}^{\mathrm{n}} \operatorname{Costs}(\mathrm{i})+\sum_{\mathrm{j}=1}^{\mathrm{m}} \text { Costs (j) }
\end{aligned}
$$

Weinstein and Zeckerhauser [31] showed that decision rules of cost-effectiveness analysis can yield the maximum total effectiveness subject to a budget constraint when several independent treatments for different health problems are included in a cost-effectiveness league table $[4,13]$.

\section{Ranking of Priorities Based on Cost-Effectiveness and a SWF}

In societies with aversion to inequality in the distribution of health outcomes among different groups of patients, the framework to set priorities based on cost-effectiveness could not maximize health-related social welfare because costeffectiveness league tables do not take into account how resources are distributed among different groups of patients. The framework to set priorities based on cost-effectiveness and a social welfare function can solve this problem, and maximize health-related social welfare, by taking into account a social welfare function explaining health-related social welfare as a function of the distribution of health gains among different groups of patients.

The health-related social welfare function considered in this framework relates social welfare (W) to a vector of individual health gains $(\mathrm{H})$ :

$\mathrm{W}=\mathrm{f}\left(\mathrm{H}_{1}, \mathrm{H}_{2}, \ldots, \mathrm{H}_{\mathrm{n}}\right)$

Under the utilitarian approach, social welfare depends on the sum of individual health-related gains:

$\mathrm{W}=\mathrm{f}\left(\mathrm{H}_{1}+\mathrm{H}_{2}+\ldots+\mathrm{H}_{\mathrm{n}}\right)$ 
In a utilitarian society, utility $(\mathrm{U})$ from the distribution of health-related gains between two groups of patients $\left(\mathrm{H}_{1}, \mathrm{H}_{2}\right)$ depends on the sum of individual health-related gains:

$\mathrm{U}\left(\mathrm{H}_{1}, \mathrm{H}_{2}\right)=\mathrm{f}\left(\mathrm{H}_{1}, \mathrm{H}_{2}\right)=\alpha \mathrm{H}_{1}+(1-\alpha) \mathrm{H}_{2}$

where $\alpha$ and $1-\alpha$ are the proportions of individuals from patient groups 1 and 2, respectively, and represent the weights for health-related gains for each group [7, 14, 32].

Under an alternative, non-utilitarian approach, aversion to inequality is permitted in the distribution of health-related gains between patient groups, and health-related social welfare depends on both efficiency and the distribution of health-related gains in the population $[15,32]$. The healthrelated social welfare function considered in this study is the following:

$\mathrm{W}=\left(\mathrm{p}_{1} \mathrm{H}_{1}{ }^{1-\varepsilon}+\mathrm{p}_{2} \mathrm{H}_{2}{ }^{1-\varepsilon}\right)^{1 / 1-\varepsilon}$

Parameter $\varepsilon$ determines the exact form of the healthrelated social welfare function and depends on the degree of aversion to inequality in the distribution of health gains between both groups of patients. In this equation, $\mathrm{p}_{1}$ and $\mathrm{p}_{2}$ are the proportions of individuals from both groups of patients included in the intervention. The parameter $\varepsilon$ can vary between 0 and $\infty$. In a utilitarian society, parameter $\varepsilon$ is equal to 0 , and total utility depends solely on the sum of individual utilities. In a non-utilitarian societies, on the other hand, $\varepsilon$ is $>0[7,18]$. Values of $\varepsilon$ obtained in different countries ranged between 0.5 and 7 [32-35].

The framework to set priorities based on costeffectiveness and the social welfare function is developed by means of the following steps [32]: 1) setting priorities based on cost-effectiveness; 2) determining values of $\varepsilon$ for available therapies when the ranking of priorities based on cost-effectiveness for mutually exclusive therapies is changed, and a higher priority is given to less cost-effective independent therapies than to more cost-effective mutually exclusive therapies; 3 ) the ranking of priorities is decided by giving a higher priority to the selection of therapies associated with a value of $\varepsilon$ consistent with the social welfare function in the society. If $\varepsilon>0$, one or more independent therapies can have a higher priority than more cost-effective mutually exclusive therapies. Health-related social welfare is maximized using this framework in nonutilitarian societies because it can achieve a more equal distribution of health gains than using cost-effectiveness league tables.

\section{Application of the Two Frameworks}

The two frameworks are applied to decide allocation of a fixed budget among eight hypothetical treatments (A to F) that should be given to individuals detected by developing specific preventive interventions. Treatments $A^{*}, C^{*}$, and $\mathrm{D}^{*}$ are mutually exclusive ones for the same group of patients, and treatments $\mathrm{B}, \mathrm{E}$ and $\mathrm{F}$ are independent ones for different groups of patients. Treatments $\mathrm{A}^{*}, \mathrm{C}^{*}$, and $\mathrm{D}^{*}$ are mutually exclusive because only one of them must be provided depending on available resources. Independent treatments include, for example, the following: treatment of patients detected with hypertension, treatment of cancer in individuals detected by developing a screening program, treatment of patients detected with hypercholesterolemia, or treatment with an orphan drug of patients detected with a rare disease [36, 37]. Mutually exclusive treatments include, for example, different smoking cessation therapies, hypertension therapies and cancer treatments. The ranking of priorities is determined using the hypothetical cost and effectiveness per patient (QALYs gained). It is assumed that all groups of patients include 1000 individuals.

In the framework based on cost-effectiveness, the ranking of priorities is determined using average costeffectiveness ratios for independent treatments and incremental cost-effectiveness ratios for mutually exclusive treatments. In the framework based on cost-effectiveness and equity, the ranking of priorities is determined taking into account cost-effectiveness ratios and values of $\varepsilon$ associated with different distributions of resources, giving a higher priority to the selection of treatments associated with a value of $\varepsilon$ consistent with the social welfare function. Assuming a value of $\varepsilon>0$, a higher priority should be given to independent treatments $\mathrm{E}$ and $\mathrm{F}$ than to more cost-effective mutually exclusive treatments $\mathrm{C}^{*}$ or $\mathrm{D}^{*}$, since then the distribution of health gains among different groups of patients is more equitably than using the framework based on cost-effectiveness. The optimal selection of treatments depends on the value of $\varepsilon$.

\section{RESULTS}

\section{Ranking of Priorities Based on Cost-Effectiveness}

Based on cost-effectiveness, the ranking of priorities is $A^{*}, B, C^{*}, D^{*}, E$ and $F$. Resources should be allocated to these treatments from the most cost-effective one (A) until they are exhausted while selecting only one mutually exclusive treatment $\left(\mathrm{A}^{*}, \mathrm{C}^{*}\right.$ or $\left.\mathrm{D}^{*}\right)$ (Table 1). Treatments $\mathrm{A}^{*}$ and $\mathrm{B}$ would be provided with a budget of 0.20 million $€$, treatments $\mathrm{B}$ and $\mathrm{C}^{*}$ with 0.24 million $€$, treatments $\mathrm{B}$ and $\mathrm{D}^{*}$ with 0.29 million $€$, treatments $\mathrm{B}, \mathrm{D}^{*}$ and $\mathrm{E}$ with 0.84 million $€$, and treatments $\mathrm{B}, \mathrm{D}^{*}, \mathrm{E}$ and $\mathrm{F}$ with 1.84 million $€$ (Table 2). The cost-effectiveness cutoff increases as the budget increases. Mutually exclusive treatments $\mathrm{C}^{*}$ and $\mathrm{D}^{*}$ are prioritized over independent treatments $\mathrm{E}$ and $\mathrm{F}$ due to their higher cost-effectiveness. For this reason, treatments $\mathrm{E}$ and $\mathrm{F}$ could be provided using this framework only after selecting treatment $\mathrm{D}^{*}$.

Table 2 shows that the framework based on costeffectiveness maximizes health gains from available resources, since total health gains are always equal or higher than those gained using the framework based on costeffectiveness and equity. The reason is that treatments with lower cost-effectiveness ratios produce health gains at lower cost than do other treatments with higher cost-effective ratios.

\section{Ranking of Priorities Based on Cost-Effectiveness and a SWF}

The ranking of priorities based on cost-effectiveness and equity is determined by taking into account costeffectiveness ratios and values of $\varepsilon$ of the social welfare function associated with different distributions of resources and health gains among different groups of patients. Values of $\varepsilon$ were determined by solving the following social welfare function:

$\mathrm{W}=\left(\mathrm{p} \mathrm{H}_{\mathrm{D}}{ }^{1-\varepsilon}+(1-\mathrm{p}) \mathrm{H}_{\mathrm{X}}{ }^{1-\varepsilon}\right)^{1 / 1-\varepsilon}$ 
Table 1. Ranking of Priorities for Six Treatments (A to F) Using the Framework to Set Priorities Based on Cost-Effectiveness and Using the Framework Based on Cost-Effectiveness and a Social Welfare Function

\begin{tabular}{|c|c|c|c|c|c|c|c|}
\hline \multirow{3}{*}{ Treatment } & \multicolumn{4}{|c|}{ Prioritisation Based on Cost-Effectiveness } & \multicolumn{3}{|c|}{ Prioritisation Based on Cost-Effectiveness and Equity } \\
\hline & \multirow{2}{*}{ Cost per Patient } & \multirow{2}{*}{ QALYs Per Patient } & \multirow{2}{*}{ Cost/QALY } & \multirow{2}{*}{ Ranking of Priorities ${ }^{\mathrm{a}}$} & \multirow{2}{*}{ Value of $\varepsilon^{b}$} & \multicolumn{2}{|c|}{ Ranking of Priorities } \\
\hline & & & & & & $\varepsilon=1.2$ in the Society & $\varepsilon=2.5$ in the Society \\
\hline $\mathrm{A}^{*}$ & 100 & 0.3 & 333 & 1 & 0.0 & 1 & 1 \\
\hline B & 105 & 0.3 & 350 & 2 & 0.0 & 2 & 2 \\
\hline $\mathrm{C}^{*}$ & 140 & 0.4 & 400 & 3 & 0.0 & 3 & 5 \\
\hline $\mathrm{D}^{*}$ & 190 & 0.5 & 500 & 4 & 0.0 & 6 & 6 \\
\hline $\mathrm{E}$ & 550 & 1.0 & 550 & 5 & $1.2 / 2.5$ & 4 & 3 \\
\hline F & 1000 & 1.0 & 1000 & 6 & $1.2 / 2.5$ & 5 & 4 \\
\hline
\end{tabular}

Treatments B, E and F are independent ones that should be provided for different groups of patients, and treatments $\mathrm{A}^{*}, \mathrm{C}^{*}$ and $\mathrm{D}^{*}$ are mutually exclusive treatments for the same group of patients.

${ }^{a}$ Ranking of priorities based on average cost-effectiveness ratios for independent treatments (total cost/total effectiveness) and incremental cost-effectiveness ratios for mutually exclusive treatments (incremental cost-effectiveness of treatment $\mathrm{C}=\operatorname{cost}_{\mathrm{C}}$ - $\operatorname{cost}_{\mathrm{A}} /$ effectiveness $_{\mathrm{C}}$-effectiveness ${ }_{\mathrm{A}}$, incremental cost-effectiveness of treatment $\mathrm{D}=$ cost $_{\mathrm{D}}$ $\operatorname{cost}_{\mathrm{C}} /$ effectiveness $\mathrm{D}_{\mathrm{D}}$-effectiveness $\mathrm{C}$ )

${ }^{\mathrm{b}}$ Value of $\varepsilon^{=1.2}$ giving a higher priority to treatments $\mathrm{E}$ and $\mathrm{F}$ than to $\mathrm{C}^{*}$ and $\mathrm{D}^{*} ; \varepsilon=2.5$ giving a higher priority to treatments $\mathrm{E}$ and $\mathrm{F}$ than $\mathrm{C}^{*}$ but a lower than $\mathrm{D}^{*}$.

Table 2. Total Costs and Total Effects Using the Framework to Set Priorities Based on Cost-Effectiveness and Using the Framework Based on Cost-Effectiveness and Equity

\begin{tabular}{|c|c|c|c|c|c|c|c|c|}
\hline \multicolumn{6}{|c|}{ Prioritisation Based on Cost-Effectiveness } & \multicolumn{3}{|c|}{ Prioritisation Based on Cost-Effectiveness and Equity $(\varepsilon=2.5)$} \\
\hline \multirow{2}{*}{ Ranking of Priorities } & \multirow{2}{*}{ No. of Patients } & \multirow{2}{*}{ Total Costs } & \multirow{2}{*}{ Total QALYs } & \multicolumn{2}{|c|}{ Aggregated Values } & \multirow{2}{*}{ Ranking of Priorities } & \multicolumn{2}{|c|}{ Aggregated Values } \\
\hline & & & & Costs & QALYs & & Costs & QALYs \\
\hline$A^{*}$ & 1,000 & 100,000 & 300 & 100,000 & 300 & $\mathrm{~A}^{*}$ & 100,000 & 300 \\
\hline B & 1,000 & 105,000 & 300 & 205,000 & 600 & B & 205,000 & 600 \\
\hline $\mathrm{C}^{*}$ & 1,000 & 140,000 & 400 & 245,000 & 700 & E & 755,000 & 1,600 \\
\hline $\mathrm{D}^{*}$ & 1,000 & 190,000 & 500 & 295,000 & 800 & $\mathrm{~F}$ & $1,755,000$ & 2,600 \\
\hline E & 1,000 & 550,000 & 1,000 & 845,000 & 1,800 & $\mathrm{C}^{*}$ & $1,795,000$ & 2,700 \\
\hline $\mathrm{F}$ & 1,000 & $1,000,000$ & 1,000 & $1,845,000$ & 2,800 & $\mathrm{D}^{*}$ & $1,845,000$ & 2,800 \\
\hline
\end{tabular}

Treatments B, E and F are independent ones that should be provided for different groups of patients, and treatments $\mathrm{A}^{*}$, C* and $\mathrm{D}^{*}$ are mutually exclusive treatments for the same group of patients.

In this equation, $H_{D}$ are health-related gains per individual achieved with treatment $\mathrm{D}^{*}$, and $\mathrm{H}_{\mathrm{X}}$ are healthrelated gains per individual achieved with treatments $\mathrm{E}$ or $\mathrm{F}$. Health-related social welfare $\mathrm{W}$ depends on health gains per individual achieved with treatment $\mathrm{A}^{*}$ or $\mathrm{C}^{*}$ instead of $\mathrm{D}^{*}$, in one group of patients, and with treatments $E$ and $F$ in other groups of patients. The value of $\mathrm{W}$ is obtained from $\mathrm{W}=\mathrm{p} \mathrm{H}_{\mathrm{A}}+(1-\mathrm{p}) \mathrm{H}_{\mathrm{X}}$, when treatment $\mathrm{A}^{*}$ is selected instead of $D^{*}$, and from $\mathrm{W}=\mathrm{p} \mathrm{H}_{\mathrm{C}}+(1-\mathrm{p}) \mathrm{H}_{\mathrm{X}}$, when treatment $\mathrm{C}^{*}$ is selected instead of $D^{*}$. Coefficients $p$ and $(1-p)$ in the social welfare function equation is equal to 0.5 since all groups of patients include 1000 individuals.

Table 3 presents values of $\varepsilon$ obtained giving a higher priority to less cost-effective independent treatments $\mathrm{E}$ and $\mathrm{F}$ than to more cost-effective mutually exclusive treatments $\mathrm{C}^{*}$ and $\mathrm{D}^{*}$. The value of $\varepsilon$ is 2.5 giving a higher priority to $\mathrm{E}$ and $\mathrm{F}$ than to $\mathrm{C}^{*}$; and $\varepsilon=1.2$ giving a higher priority to $\mathrm{E}$ and $\mathrm{F}$ than $\mathrm{D}^{*}$ but a lower than $\mathrm{C}^{*}$. The value of $\varepsilon$ is 0 giving a higher priority to treatment $\mathrm{D}^{*}$ than $\mathrm{E}$ and $\mathrm{F}$ since this selection is consistent with decision rules of cost- effectiveness analysis. The optimal selection of treatments based on cost-effectiveness and equity depends on the value of $\varepsilon$ representative of the society. Assuming that the value of $\varepsilon$ in the society is 2.5 , the optimal selection is $\mathrm{A}^{*}, \mathrm{~B}, \mathrm{E}, \mathrm{F}$, $\mathrm{C}^{*}$ and $\mathrm{D}^{*}$, while assuming a value of $\varepsilon=1.2$, the optimal selection is $\mathrm{A}^{*}, \mathrm{~B}, \mathrm{C}^{*}, \mathrm{E}, \mathrm{F}$ and $\mathrm{D}^{*}$ (Tables $\mathbf{1}$ and $\mathbf{2}$ ).

The framework based on cost-effectiveness and the SWF could maximize health-related social welfare in both utilitarian and non-utilitarian societies. In a non-utilitarian society, health-related social welfare is maximized by giving a higher priority to treatments $\mathrm{E}$ and $\mathrm{F}$ than to $\mathrm{C}^{*}$ and $\mathrm{D}^{*}$ since this selection can reduce inequality in the distribution of health gains among different groups of patients. In a utilitarian society, on the other hand, the ranking of priorities based on cost-effectiveness and equity is consistent with the ranking based on cost-effectiveness. Table 2 shows also that the framework based on cost-effectiveness and equity is associated with a lower cost of treating all patients (1.7 million $€)$ than using the framework based on costeffectiveness (1.8 million $€$ ). 


\section{DISCUSSION}

The health system has to cope with a limited amount of resources for drug therapies, and a growing number of academics and policy-makers are suggesting that strategies of prioritization should be based on both cost-effectiveness and equity. This study provides health care managers with the frameworks necessary to implement these prioritization strategies in public and insurance-based health care systems.

This study shows that cost-effectiveness league tables can provide comprehensive and valid information to assist decisions on the allocation of resources for drug therapies if equity is incorporated using appropriate approaches. Priority-setting frameworks must be used when resources are limited and many drug therapies are available. Nevertheless, in most countries, health care resources are distributed without considering scarcity of resources and efficiency and equity implications. For example, when a new drug is approved, regulatory committees may require economic evaluations and budget impact analysis to support coverage and reimbursement decisions, but the implications of these decisions on the efficiency and equity of the health care system is not assessed. The main reason is decisions regarding reimbursement for new drugs, and the distribution of the health budget, are made in circumstances where the budget constraint is implicit rather than explicit $[5,36]$. There is not a fixed budget that must be distributed for all available drug therapies and groups of patients, with different efficiency and equity implications depending on how this distribution is made. For drug therapies, however, there is no reason to not incorporate priority-setting frameworks to decide allocation of resources, since budget constraints can be explicit.

Weinstein [5] indicated that cost-effectiveness league tables should not include different drug therapies for the same group of patients. Masson, Drummond, and Torrance [13] indicated, in their paper questioning cost-effectiveness league tables that they would be less likely to argue against the use of cost-effectiveness league tables if they included drug therapies for the same group of patients. This study shows, however, that independent and mutually exclusive drug therapies can be compared in a cost-effectiveness league table, since distributional problems can be solved using the cost-effectiveness or the decision maker's approach in utilitarian and non-utilitarian societies, respectively.

Priority-setting frameworks could be used in the following situations: 1) when the budget constraint is explicit - that is, when scarce resources must be distributed among new drugs and among available drug therapies for different groups of patients; 2) when the budget constraint is implicit, that is, when resources are not explicitly limited, but one of the objectives of the health system is to control and reduce health care costs. In these situations, medical and social decision makers could decide which of the frameworks presented in this study should be used. In a utilitarian society, the framework based on cost-effectiveness is the most appropriate since it will maximize effectiveness from available resources. In these societies, it does not matter how outcomes are distributed. If it is decided to consider that QALYs can have different social values, the framework based on cost-effectiveness with corrected
QALYs will maximize corrected QALYs. In a non-utilitarian society, setting priorities using the cost-effectiveness framework may not maximize health-related social welfare because it is necessary to take into account how resources are distributed. In these societies, the framework based on cost-effectiveness and the social welfare function is the most appropriate to maximize health-related social welfare, since treating more groups of patients with at least one therapy is associated with higher health-related social welfare than treating fewer patients using more costly drug therapies.

To apply the social welfare function approach in a specific country, however, it is necessary to estimate the country-specific value of $\varepsilon$ of the social welfare function, and to calculate health-related social welfare implications when scarce resources are allocated among competing therapies. The exact form of the social welfare function can be determined by means of developing logistic regression analysis to assess preferences concerning the efficiency-equity trade-off [32]. Further research is therefore necessary to estimate preferences for efficiency and equity in different countries.

The framework based on cost-effectiveness and a social welfare function developed in this study can be used to set priorities based on both efficiency and equity. Other approaches proposed to set priorities based on efficiency and equity includes the use of socially corrected QALYs and multifactorial frameworks [1, 38]. Several authors have suggested that QALYs could be corrected for social preferences in order to incorporate equity into the costeffectiveness framework [38-42]. This approach, however, has been proposed to decide priorities between two therapies for two different groups of patients, rather than across a number of independent and mutually exclusive drug therapies for different groups of patients [1,38]. This approach could obtain a ranking of priorities based on the cost per corrected QALY, but the ranking of priorities then could not account for the aversion to inequality in the distribution of healthrelated gains among different groups of patients. The reason is that corrected QALYs do not take into account how health-related gains are distributed among different groups of patients when multiple independent and mutually exclusive drug therapies are available.

Several authors have proposed multicriteria frameworks to decide priorities $[20,21,23]$. This approach requires the formation of a multi-disciplinary panel whose members identify attributes, define descriptors and measurement scales for these attributes, and make the assessment. The ranking of priorities could be determined by comparing costs and benefits $[20,21]$ or by comparing the overall value of competing drug therapies $[23,43,44]$. This approach has been proposed to decide priorities only across a number of independent drug therapies [20, 21, 23, 43, 44]. The ranking of priorities based on a multifactorial approach, on the other hand, is obtained using a qualitative evaluation of the effectiveness, and cannot account for the aversion to inequality in the distribution of health-related gains among different groups of patients.

The National Institute for Health and Clinical Excellence (NICE) of the United Kingdom assesses cost-effectiveness of drug therapies via a utilitarian approach; that is, assuming that a QALY gained with respect to one disease is equivalent to a QALY gained with respect to another [28]. Therefore, 
Table 3. Values of $\varepsilon$ of the Social Welfare Function Obtained Selecting Treatments $E$ and $F$ After Reatments $A^{*}$, C* and $D^{*}$. Treatments B, E and F are Independent Ones that should be Provided for Different Groups of Patients, and Treatments $A^{*}, C^{*}$ and $D^{*}$ are Mutually Exclusive Treatments for the Same Group of Patients

\begin{tabular}{|c|c|c|c|c|}
\hline Treatment & Health-Related Social Welfare $\mathbf{W}^{\mathrm{b}}$ & QALYs Per Patient with Treatment D $\mathrm{H}_{\mathrm{D}}$ & QALYs Per Patient with $E$ and $F H_{X}$ & Value of $\varepsilon^{2}$ \\
\hline \multicolumn{5}{|c|}{ Selecting Treatments E and F After Treatment $A^{*}$} \\
\hline $\mathrm{E}$ & 0.65 & 0.5 & 1.0 & 2.5 \\
\hline $\mathrm{E}$ & 0.70 & 0.5 & 1.0 & 1.2 \\
\hline $\mathrm{F}$ & 0.70 & 0.5 & 1.0 & 1.2 \\
\hline \multicolumn{5}{|c|}{ Selecting Treatments E and F After Treatment $D^{*}$} \\
\hline $\mathrm{E}$ & 0.75 & 0.5 & 1.0 & 0.0 \\
\hline
\end{tabular}

${ }^{a}$ Values of $\varepsilon$ are obtained by solving the social welfare function $W=\left(\mathrm{p} \mathrm{H}_{\mathrm{D}}^{1-\varepsilon}+(1-\mathrm{p}) \mathrm{H}_{\mathrm{X}}{ }^{1-\varepsilon}\right)^{1 / 1-\varepsilon}$

${ }^{b} \mathrm{p}$ is the proportion of individuals from the two groups of patients. It is assumed that $\mathrm{p}=(1-\mathrm{p})=0.5$

Health-related social welfare $\mathrm{W}$ is obtained from $\mathrm{W}=\mathrm{p} \mathrm{H}_{\mathrm{A}}+(1-\mathrm{p}) \mathrm{H}_{\mathrm{X}}$ when treatment $\mathrm{A}^{*}$ is selected instead of $\mathrm{D}^{*}$, and from $\mathrm{W}=\mathrm{p} \mathrm{H}_{\mathrm{C}}+(1-\mathrm{p}) \mathrm{H}_{\mathrm{X}}$ when treatment $\mathrm{C}$ is selected instead of $\mathrm{D}^{*}$. Health gains per individual with treatment $\mathrm{A}^{*}: \mathrm{H}_{\mathrm{A}}=0.3$ : Health gains per individual with treatment $\mathrm{c}^{*}: \mathrm{H}_{\mathrm{C}}=0.4$.

the weight given to the gain of a QALY is the same for all groups of patients without regard to distribution of healthrelated gains. This approach is consistent for assessing whether an individual drug therapy is worth its costs compared with others. The Kennedy report [45] questioned the National Health Service (NHS) and NICE priority setting frameworks because they give a low priority to services and therapies for children and young people. In the NHS of the United Kingdom and other developed countries, costeffectiveness and burden of disease are possibly the key factors determining priorities. Consequently, based on these criteria, costly therapies for disabled children and rare diseases could have a low priority. The Board of the NICE [46] indicated, however, that its current emphasis on achieving both clinical and cost-effective care for NHS patients should continue, although draws a distinction between advising on cost-effectiveness within the resources available for health care, and affordability, which is considered a responsibility of the government. This study shows that therapies for children and rare diseases could have a higher priority than other more cost-effective therapies for adults if priorities were determined taking into accounts both cost-effectiveness and health-related social welfare.

In most societies, when resources must be distributed across a number of independent and mutually exclusive therapies, the ranking of priorities based on costeffectiveness should be adjusted for equity in the distribution of health-related gains. In most societies, the parameter $\varepsilon$ in the social welfare function, which depends on the degree of aversion to inequality in the distribution of health-related gains, might be $>0$. Based on the health-related social welfare approach, higher priority should be given to pharmaceutical therapies with a value of $\varepsilon$ consistent with the social welfare function.

\section{CONCLUSION}

The two frameworks developed in this study could be used to set priorities for multiple drug therapies depending on social preferences for the distribution of health-related gains among different groups of patients. The framework based on cost-effectiveness (league tables) could be used in utilitarian societies, and the framework based on costeffectiveness and equity could be used in non-utilitarian societies.

\section{CONFLICT OF INTEREST}

Declared None.

\section{ACKNOWLEDGEMENT}

Declared None.

\section{REFERENCES}

[1] Brouwer WBF, Koopmanschap MA. On the economic foundations of CEA. Ladies and gentlemen, take your positions! J Health Econ 2000; 19: 439-59.

[2] Torrance GW. Measurement of health state utilities for economic appraisal: a review. J Health Econ 1986; 5: 1-30.

[3] Maynard A. Developing the health care market. J Econ 1991; 101: 1277-86.

[4] Gold MR, Siegel JE, Russell LB, Weinstein MC, Eds. Costeffectiveness in health and medicine. New York: Oxford University Press 1996.

[5] Weinstein MC. From cost-effectiveness ratios to resource allocation; where to draw the line? In: Sloan FA, Ed. Value Health Care. New York: Cambridge University Press 1998.

[6] Cuyler AJ. The normative economics of health care finance and provision. In: McGuire A, Fenn P, Mayhew K, Eds. Providing health care: the economics of alternative systems of finance and delivery. Oxford: Oxford University Press 1991.

[7] Wagstaff A. QALY and the equity-efficiency trade-off. J Health Econ 1991; 10: 21-41.

[8] Birch S, Gafni A. Cost-effectiveness/utility analysis: do current decision rules lead us to where we want to be? J Health Econ 1992; 11: 279-96.

[9] Birch S, Gafni A. Cost-effectiveness ratios: in a league of their own. Health Policy 1994; 28: 133-41. 
[10] Cuyler AJ, Wagstaff A. Equity and equality in health and health care. J Health Econ 1993; 12: 431-57.

[11] Drummond MF, Mason JM, Torrance GW. Cost-effectiveness league tables: more harm than good? Soc Sci Med 1993; 37: 33-40.

[12] Drummond M, Mason J, Torrance G. Cost-effectiveness league tables: think of the fans. Health Policy 1995; 31:231-8.

[13] Mason J, Drummond M, Torrance G. Some guidelines on the use of cost effectiveness league tables. Br Med J 1993; 306: 570-2.

[14] Nord E, Richardson J, Street A, Kushe A, Singer P. Maximizing health benefits $v s$ egalitarianism: an Australian survey of health issues. Soc Sci Med 1995; 41: 1429-37.

[15] Dolan P. The measurement of individual utility and social welfare. J Health Econ 1998; 17: 39-52.

[16] Williams A, Cookson R. Equity in health. In: Cuyler AJ, Newhouse JP, Eds. Handbook of health economics. Amsterdam: Elsevier 2000.

[17] Daniels N. Justice, health, and healthcare. Am J Bioeth 2001; 1: 216

[18] Dolan P, Olsen JA. Distributing health care: economic and ethical issues. Oxford: Oxford University Press 2002.

[19] Brock DW. Ethical issues in the use of cost-effectiveness analysis for the prioritisation of health care resources. In: Sudhir A, Fabienne P, Sen A, Eds. Public health, ethics and equity. Oxford: Oxford University Press 2004.

[20] Mitton C, Donaldson C. Setting priorities and allocating resources in health regions: lessons from a project evaluating program budgeting and marginal analysis (PBMA). Health Policy 2003; 64: $335-48$.

[21] Mitton C, Donaldson C. Health care priority setting: principles, practice and challenges. Cost Eff Resour Alloc 2004; 2: 3-10.

[22] Mooney G. Communitarian claims and community capabilities: furthering priority setting? Soc Sci Med 2005; 60: 247-55.

[23] Baltussen R, Niessen L. Priority setting of health interventions: the need for multiple-criteria decision analysis. Cost Eff Resour Alloc 2006; $4: 14$.

[24] Richardson J, McKie J. Economic evaluation of services for a national health scheme: the case of a fairness-based framework. J Health Econ 2007; 26: 785-99.

[25] Peacock S, Ruta D, Mitton C, Donaldson C, Bate A, Murtagh M. Using economics for pragmatic and ethical priority setting: two checklists for doctors and managers. Br Med J 2007; 332: 482-5.

[26] Persad G, Werthiemer A, Emanuel EJ. Principles of allocation of scarce medical interventions. Lancet 2009; 373: 423-31.

[27] Laupacis A, Feeny D, Detsky AS, Tugwell PX. How attractive does a new technology have to be to warrant adoption and utilization? Tentative guidelines for using clinical and economical evaluations. CMAJ 1992; 146: 473-81.

[28] Rawlins MD, Cuyler AJ. National institute of clinical excellence and its value judgements. Br Med J 2004; 329: 224-7.

[29] Weinstein MC. How much are Americans willing to pay for a qualityadjusted life year? Med Care 2008; 46: 343-5.
[30] Rocchi A, Menon D, Verma S, Miller E. The role of economic evidence in Canadian oncology reimbursement decision making: to lambda and beyond. Value Health 2007; 11: 771-83.

[31] Weinstein MC, Zeckerhauser RJ. Critical ratios and efficient allocation. The economics of public health. Philadelphia: University of Philadelphia Press 1961.

[32] Plans-Rubió P. Allocation of resources between smoking cessation methods and lovastatin treatment of hypercholesterolemia based on cost-effectiveness and the social welfare function. Pharmacoeconomics 2004; 22: 55-69.

[33] Johannesson M, Gerdtham U-G. A note on the estimation of the equity-efficiency trade-off for QALYs. J Health Econ 1996; 15 359-68.

[34] Lindholm L, Rosén M. On the measurement of the nation's equity adjusted health. Health Econ 1998; 7: 621-8.

[35] Anderson F, Lyttkens CH. Preferences for equity in health behind a veil of ignorance. Health Econ 1999; 8: 369-78.

[36] Detsky AS, Laupacis AP. Relevance of cost-effectiveness analysis to clinicians and policy makers. JAMA 2007; 298: 221-4.

[37] List of Orphan Drugs in Europe. Orphanet Report Series, Orphan Drugs Collection, January 2011. Available from: http:/www.orpha n.net/orphancom/cahiers/dics/GB

[38] Nord E. Cost-value analysis in health care: making sense of QALYs. New York: Cambridge University Press 1999.

[39] Bleichrodt $\mathrm{H}$. Health utility indices and equity considerations. J Health Econ 1997; 16: 65-91.

[40] Bleichrodt H, Herrero C, Pinto JL. A proposal to solve the comparability problem in cost-utility analysis. J Health Econ 2002; 21: 397-403.

[41] Abasolo I, Tsuchiya A. Exploring social welfare functions and violation of monotonicity: an example from inequalities in health. J Health Econ 2004; 23: 313-29.

[42] Wailoo A, Tsuchiya A, McCabe C. Weighting must wait: incorporating equity concerns into cost-effectiveness analysis may take longer than expected. Pharmacoeconomics 2009; 27: 983-9.

[43] Goetghebeur MM, Wagner M, Khoury H, Rindress D, Grégoire J, Deal C. Combining multicriteria decision analysis, ethics and health technology assessment: applying the EVIDEM decision making framework to growth. Cost Eff Resour Alloc 2010; 8: 4-19.

[44] Jehu-Appiah C, Baltussen R, Acquah C, et al. Balancing equity and efficiency in health priorities in Ghana: the use of multicriteria decision analysis. Value Health 2008; 11: 1081-7.

[45] Bristol Royal Infirmary Inquiry. Learning from Bristol: the report of the public inquiry into children's heart surgery at the Bristol Royal Infirmary 1984 -1995 (Kennedy report). Bristol: Bristol Royal Infirmary Inquiry, 2001. Available from: http://www.bristolinquiry. org.uk/final_ report/the report.pdf

[46] NICE. Response to Kennedy report (Bristol inquiry). 21 September 2001 (updated 30 April 2009). Available from: http://www.nice. org.uk/niceMedia/pdf/bristolreportresponsefinal.pdf 